\title{
AcnC of Escherichia coli is a 2-methylcitrate dehydratase (PrpD) that can use citrate and isocitrate as substrates
}

\author{
Lindsay Blank, Jeffrey Green and John R. Guest
}

Author for correspondence: John R. Guest. Tel: +44 114 2224406. Fax: +44 1142728697.

e-mail: j.r.guest@sheffield.ac.uk

The Krebs Institute for Biomolecular Research, Department of Molecular Biology and Biotechnology, University of Sheffield, Western Bank, Sheffield S10 2TN, UK

\begin{abstract}
Escherichia coli possesses two well-characterized aconitases (AcnA and AcnB) and a minor activity (designated $A c n C$ ) that is retained by acnAB double mutants and represents no more than $5 \%$ of total wild-type aconitase activity. Here it is shown that a 2-methylcitrate dehydratase (PrpD) encoded by the prpD gene of the propionate catabolic operon (prpRBCDE) is identical to AcnC. Inactivation of prpD abolished the residual aconitase activity of an AcnAB-null strain, whereas inactivation of $y b h J$, an unidentified acnA paralogue, had no significant effect on AcnC activity. Purified PrpD catalysed the dehydration of citrate and isocitrate but was most active with 2-methylcitrate. PrpD also catalysed the dehydration of several other hydroxy acids but failed to hydrate cis-aconitate and related substrates containing double bonds, indicating that PrpD is not a typical aconitase but a dehydratase. Purified PrpD was shown to be a monomeric iron-sulphur protein $\left(M_{r} 54000\right)$ having one unstable [2Fe-2S] cluster per monomer, which is needed for maximum catalytic activity and can be reconstituted by treatment with $\mathrm{Fe}^{2+}$ under reducing conditions.
\end{abstract}

Keywords: aconitase, iron-sulphur proteins, propionate metabolism, YbhJ

\section{INTRODUCTION}

Aconitases (EC 4.2.1.3) catalyse the reversible isomerization of citrate and isocitrate via cis-aconitate in the citric acid and glyoxylate cycles. They are monomeric enzymes containing single, unstable $[4 \mathrm{Fe}-4 \mathrm{~S}]$ centres which are reversibly converted to inactive $[3 \mathrm{Fe}-4 \mathrm{~S}]$ and apo-enzyme forms (Beinert et al., 1996). Crystallographic studies with porcine and bovine mitochondrial aconitases (mit-Acn) have revealed an arrangement of four structural domains (1-2-3-linker-4) in which three domains surround the $[4 \mathrm{Fe}-4 \mathrm{~S}]$ cluster and the fourth domain is connected by a long linker such that a deep active-site cleft is formed between domain 4 and the rest of the protein (Robbins \& Stout, 1989; Lauble et al., 1992). The mit-Acn structure is the structural archetype for all members of the aconitase family, which includes: aconitases; homoaconitases; isopropylmalate isomerases; bifunctional cytoplasmic aconitase-iron regulatory proteins (c-Acn/IRP1); and monofunctional iron

\footnotetext{
Abbreviations: Acn, aconitase; c-Acn, cytoplasmic aconitase; mit-Acn, mitochondrial aconitase; AcnC, the residual Acn activity of an AcnAB-null strain; IRP, iron regulatory protein; PrpD, 2-methylcitrate dehydratase; UTR, untranslated region.
}

regulatory proteins (IRP2) (Gruer et al., 1997a). Escherichia coli contains two well-characterized aconitases, $A c n A$ and $A c n B$, encoded by genes located at $28 \mathrm{~min} /$ $1350 \mathrm{~kb}(a c n A)$ and $2.85 \mathrm{~min} / 131 \mathrm{~kb}(a c n B)$ in the chromosome (Prodromou et al., 1992; Bradbury et al., 1996). The AcnA protein is remarkably similar to mammalian aconitases, with sequence identities of $29 \%$ to mit-Acn and $53 \%$ to c-Acn/IRP1, whereas the AcnB protein is only $17 \%$ identical to AcnA, mit-Acn and cAcn/IRP1. The sequences also indicate that AcnB has a cyclically permuted domain organization (4-linker-1-23 ) relative to the archetypal arrangement (1-2-3-linker4) predicted for AcnA (Gruer et al., 1997a).

Biochemical and enzymological studies including studies with acn mutants and $a c n-l a c Z$ reporter fusions have established that $A c n B$ is the major citric acid cycle enzyme, synthesized during exponential growth and adapted for this role by performing better at high substrate concentrations (Gruer et al., 1997b; Cunningham et al., 1997; Jordan et al., 1999). In comparison, AcnA is a more robust stationary-phase enzyme that is specifically induced by iron and oxidative stress, presumably to maintain citric-acid-cycle functions under oxidative stress conditions. The aerobic growth of $a c n A$ mutants is essentially unimpaired in minimal medium 
with glucose and other substrates including pyruvate and acetate, indicating that the lesion is fully complemented by the $a c n B$ gene (Gruer et al., 1997b). In contrast, $a c n B$ mutants are severely impaired, and although the growth defect is partly reversed by adding glutamate, acetate cannot be used even with a glutamate supplement. However, $a c n A B$ double mutants are even more debilitated, indicating that the $a c n B$ lesion is complemented to a minor extent by the acnA gene.

The bifunctional c-Acn/IRP1 proteins of higher organisms lose their iron-sulphur clusters and catalytic activity in response to iron starvation or oxidative stress and the apo-proteins then function as site-specific mRNA-binding proteins (Beinert et al., 1996; Hentze \& Kuhn, 1996). They bind to specific stem-loop structures (iron-responsive elements, IRE) in the $5^{\prime}$ or $3^{\prime}$ UTR of relevant transcripts and either block translation or increase transcript stability (and hence translation), respectively. Recently, the apo-proteins of both E. coli aconitases (apo-AcnA and apo-AcnB) have been shown to interact with sequences in the $3^{\prime}$ UTR of $\operatorname{acn} A$ and $a c n B$ mRNA, thereby increasing mRNA stability and hence Acn synthesis, in response to oxidative disassembly of the iron-sulphur clusters (Tang \& Guest, 1999). The Bacillus subtilis aconitase (CitB) has likewise been shown to bind to rabbit ferritin IRE and to analogous sequences in relevant $B$. subtilis operons (Alen \& Sonenshein, 1999). There is also evidence that aconitase performs a regulatory role in virulence factor production in Pseudomonas aeruginosa and Xanthomonas campestris (Somerville et al., 1999; Wilson et al., 1998).

The purpose of the present work was to identify the source(s) of the aconitase activity retained by a derivative of E. coli W3110 (JRG3259) in which the acnA and $a c n B$ genes had each been totally inactivated by internal deletion and antibiotic-cassette insertion (Gruer et al., 1997b). This residual aconitase activity, designated AcnC, amounted to approximately $5 \%$ of total wildtype activity. Two potential candidates, $\operatorname{PrpD}$ and $\mathrm{YbhJ}$, were identified by partial purification of the residual activity and database searching, respectively. Evidence is presented to show that the AcnC activity can be attributed to the broad substrate specificity of $\operatorname{PrpD}$, a 2methylcitrate dehydratase that functions in the 2methylcitrate pathway of propionate utilization.

\section{METHODS}

Bacterial strains and plasmids. The strains of E. coli K-12 and the plasmids used in this work are summarized in Table 1. Strain W3110 was the major parental strain and DH5 $\alpha$ was used as the primary transformation host for genetic manipulation.

Microbiological methods. The complex medium was L broth (Lennox, 1955) supplemented with ampicillin (100 $\mathrm{mg} \mathrm{l}^{-1}$ ), tetracycline $\left(5 \mathrm{mg} \mathrm{l}^{-1}\right)$, kanamycin $\left(25 \mathrm{mg} \mathrm{l}^{-1}\right)$ and chloramphenicol $\left(10 \mathrm{mg} \mathrm{l}^{-1}\right)$ as required. In growth tests, citrate-free minimal medium (Cole \& Guest, 1980) was used with glucose $(11 \mathrm{mM})$, galactose $(22 \mathrm{mM})$ or acetate $(40 \mathrm{mM})$ as major substrate and thiamin hydrochloride $\left(5 \mathrm{mg} \mathrm{l}^{-1}\right)$. The minimal medium was supplemented with L-glutamate $(4 \mathrm{mM})$ when growing the $a c n A a c n B$ double mutant and with D-biotin $(20 \mu \mathrm{M})$ as required. Propionate $(10-50 \mathrm{mM})$ was added to rich medium to study its effect on AcnC expression. All cultures were grown aerobically at $37^{\circ} \mathrm{C}$ unless stated otherwise. For small-scale enzyme analysis bacteria were harvested from $10 \mathrm{ml}$ cultures and resuspended in $600 \mu \mathrm{l}$ Tris/ $\mathrm{HCl}$ buffer $(20 \mathrm{mM}, \mathrm{pH} 8 \cdot 0)$ at $0{ }^{\circ} \mathrm{C}$. Cell-free extracts were prepared by two ultrasonic treatments $(10 \mathrm{~s}$ at $10 \mathrm{MHz}$ separated by $30 \mathrm{~s}$ on ice) followed by the removal of cell debris by centrifugation (10000 $g$ for $5 \mathrm{~min}$ ).

Aconitase assay, reactivation and protein analysis. Aconitase activity was assayed spectrophotometrically at $\mathrm{pH} 7.4$ and $37^{\circ} \mathrm{C}$ by following the conversion of DL-isocitrate $(20 \mathrm{mM})$ to cis-aconitate at $240 \mathrm{~nm}$ using an absorption coefficient of $3.6 \mathrm{mM}^{-1} \mathrm{~cm}^{-1}$ (Kennedy et al., 1983). One unit (U) corresponds to $1 \mu \mathrm{mol}$ cis-aconitate formed $\mathrm{min}^{-1}$; activities were routinely measured before and after reactivation by adding ammonium ferrous sulphate $(0.5 \mathrm{mM})$, DTT $(5 \mathrm{mM})$ and Tris/ $\mathrm{HCl}(50 \mathrm{mM}$; $\mathrm{pH} \mathrm{8.0)}$ to the enzyme solution for $30 \mathrm{~min}$ at $0{ }^{\circ} \mathrm{C}$. In specificity studies isocitrate was replaced by other potential substrates using concentrations of $20 \mathrm{mM}$ for hydroxyacids and $0.2 \mathrm{mM}$ for potentially hydratable doublebonded substrates under the same conditions as the standard assay. When required, 2-methylcitrate was generated enzymically by incubating propionyl-CoA $(0 \cdot 6 \mathrm{mM})$, oxaloacetic acid $(0.6 \mathrm{mM})$ and Tris $/ \mathrm{HCl}(20 \mathrm{mM} \mathrm{pH} \mathrm{8.0)}$ with porcine citrate synthase $(1 \mathrm{U})$ in a final volume of $1.0 \mathrm{ml}$ for $1 \mathrm{~h}$ at $37^{\circ} \mathrm{C}$. Reactions were stopped by heating for $10 \mathrm{~min}$ at $70^{\circ} \mathrm{C}$ and clarified in a microfuge (13000 r.p.m., $10 \mathrm{~min})$. Parallel reactions with acetyl-CoA instead of propionyl-CoA were used to generate citrate, and reactions lacking each substrate served as controls. Although porcine citrate synthase is a poor 2-methylcitrate synthase compared to the Thermoplasma acidophilum enzyme (Gerike et al., 1998), the former was found to use propionyl-CoA at $2 \%$ of the rate observed with acetyl-CoA and both enzymes gave comparable products under the conditions used. The porcine enzyme was used routinely because it is more readily inactivated. 2-Methylcitrate was converted (presumably to 2 -methyl-cis-aconitate) by adding purified PrpD $(0.06 \mathrm{U})$ directly to the clarified reaction products (and controls), incubating at $37^{\circ} \mathrm{C}$ until the absorbance at $240 \mathrm{~nm}$ stopped increasing (10 min approx.), and then heating and clarifying as before.

Iron-sulphur clusters were also reconstituted by a NifSmediated procedure (Green et al., 1996). Purified PrpD

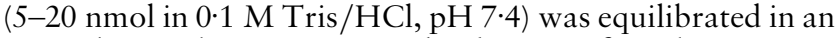
anaerobic workstation (Don Whitely Scientific, Mk3) at $25^{\circ} \mathrm{C}$ for $16 \mathrm{~h}$ before adding DTT $(5 \mathrm{mM})$, L-cysteine $(1 \mathrm{mM})$, $\left(\mathrm{NH}_{4}\right)_{2} \mathrm{Fe}\left(\mathrm{SO}_{4}\right)_{2}(10 \mathrm{~mol}$ per mol of PrpD) and NifS $(1 \mu \mathrm{M})$, in $1 \mathrm{ml}$ final volume. The reaction mixtures were sealed in quartz cuvettes and changes in the absorbance in the range 240$900 \mathrm{~nm}$ were monitored using a Unicam UV4 spectrophotometer; mixtures lacking NifS or PrpD were used as controls. For subsequent analysis, excess iron and sulphur were removed under anaerobic conditions by loading on an Ether $650 \mathrm{~S}$ column $(9 \times 12 \mathrm{mM})$ washing with high-salt buffer (2 ml $10 \mathrm{mM}$ Tris/ $\mathrm{HCl}, \mathrm{pH} 8 \cdot 0$, containing $1 \mathrm{M} \mathrm{NaCl}$ ) and eluting with low-salt buffer $(2 \mathrm{ml} 10 \mathrm{mM}$ Tris/ $\mathrm{HCl}, \mathrm{pH} 8 \cdot 0$, containing $10 \mathrm{mM} \mathrm{NaCl}$ ).

Partial purification of AcnC from an unamplified source. AcnC activity was partially purified from the AcnAB-null strain (JRG3259; acnA::kan ${ }^{\mathrm{R}} a c n B:: t^{\mathrm{R}}{ }^{\mathrm{R}}$ ) grown with vigorous aeration at $37^{\circ} \mathrm{C}$ for $8-12 \mathrm{~h}$ in six $2 \mathrm{l}$ flasks each containing $500 \mathrm{ml} \mathrm{L}$ broth supplemented with appropriate antibiotics and inoculated to give a starting $\mathrm{OD}_{600}$ of $0 \cdot 1$. The 
Table 1. E. coli strains, plasmids and phages

\begin{tabular}{|c|c|c|}
\hline $\begin{array}{l}\text { Strain or } \\
\text { plasmid }\end{array}$ & Relevant characteristics & Source or reference \\
\hline W3110 & Prototroph & Laboratory collection \\
\hline $\mathrm{DH} 5 \alpha$ & $\Delta l a c \mathrm{U} 169$ ( $\phi 80 \mathrm{lac} Z \Delta \mathrm{M} 15) \operatorname{recA} 1$ & Sambrook et al. (1989) \\
\hline DY329 & $\begin{array}{c}\Delta l a c \mathrm{U} 169 \text { nad } A:: \mathrm{Tn} 10 \text { gal490 } \lambda \text { cI857 } \\
\Delta(\text { cro-bioA }) \text { derivative of } \mathrm{W} 3110\end{array}$ & Yu et al. (2000) \\
\hline KS302 & $\mathrm{HfrH} \Delta(g a l-y b h D H I J-a t t \lambda-b i o)$ & Shimada et al. (1973) \\
\hline JRG2789 & $\operatorname{acn} A:: \operatorname{kan}^{\mathrm{R}}$ derivative of W3110 & Gruer \& Guest (1994) \\
\hline JRG3258 & $a c n B::$ tet $^{\mathrm{R}}$ derivative of $\mathrm{W} 3110$ & Gruer \& Guest (1994) \\
\hline JRG3259 & $a c n A:: k a n^{\mathrm{R}} a c n B:: t e t^{\mathrm{R}}$ derivative of $\mathrm{W} 3110$ & Gruer et al. (1997b) \\
\hline JRG4195 & $a c n A:: k a n^{\mathrm{R}} a c n B::$ tet $^{\mathrm{R}}$ derivative of $\mathrm{KS} 302$ & This work \\
\hline JRG4627 & $\operatorname{prpD}::$ cam $^{\mathrm{R}}$ derivative of DY329 & This work \\
\hline JRG4628 & $\operatorname{prpD}:: \operatorname{cam}^{\mathrm{R}}$ derivative of JRG3259 & This work \\
\hline JRG4629 & $\mathrm{Gal}^{+} \mathrm{Bio}^{+}$transductant of JRG4195 & This work \\
\hline pACYC184 & $\mathrm{Cm}^{\mathrm{R}} \mathrm{Tc}^{\mathrm{R}}$ & Chang \& Cohen (1978) \\
\hline ptac-85 & $\mathrm{Ap}^{\mathrm{R}}$ & Marsh (1986) \\
\hline pGS1575 & ptac- 85 containing $\operatorname{prpD} D^{+} ; \mathrm{Ap}^{\mathrm{R}}$ & This work \\
\hline pGS1576 & ptac-85 containing $y b h J^{+} ; \mathrm{Ap}^{\mathrm{R}}$ & This work \\
\hline
\end{tabular}

bacteria were harvested, resuspended at $4^{\circ} \mathrm{C}$ in $0 \cdot 1 \mathrm{M}$ Tris/ $\mathrm{HCl}$, pH $7 \cdot 4$ (buffer A), containing $10 \mathrm{mM}$ benzamidine, disrupted by three passes through a French pressure cell (15000 p.s.i., $103.5 \mathrm{kPa})$, and debris removed by centrifugation ( $25000 \mathrm{~g}$ for $30 \mathrm{~min}$ ). The cell-free extracts were fractionated by dye-affinity chromatography, based on the methods used for AcnA and AcnB (Bennett et al., 1995; Bradbury et al., 1996), using a Procion Red column $(20 \times 90 \mathrm{mM})$ previously equilibrated with buffer A. Bound protein was eluted at $0.5 \mathrm{ml}$ $\mathrm{min}^{-1}$ with a $50 \mathrm{ml}$ linear gradient of $0-1 \mathrm{M}$ citrate in buffer $\mathrm{A}$. Fractions were tested before and after reactivation and active fractions (eluted at 100-200 mM citrate) were pooled, desalted by dialysis in 21 buffer A (overnight), and then applied to a Procion Yellow column $(151 \times 40 \mathrm{mM}$; also equilibrated with buffer A). Active fractions were again eluted at approximately $100-200 \mathrm{mM}$ citrate using the same gradient (0-1 M citrate), pooled and stored at $-20{ }^{\circ} \mathrm{C}$ after desalting.

Purification of PrpD and YbhJ from genetically amplified strains. The PrpD and YbhJ proteins were purified from strains containing the corresponding ptac-85 expression plasmids (pGS1575 and pGS1576) in the AcnAB-null host (JRG3259); see Table 1. Cultures were grown with vigorous aeration in six 21 baffled flasks each containing $500 \mathrm{ml} \mathrm{L}$ broth. After $1 \mathrm{~h}$ at $37^{\circ} \mathrm{C}$ they were transferred to $25^{\circ} \mathrm{C}$, IPTG $\left(30 \mathrm{mg} \mathrm{l}^{-1}\right)$ was added and growth was continued for a further 8-12 h. The overproduced PrpD was isolated as described above for AcnC; the aconitase activity and enrichment in the SDS-PAGE profile were used to monitor the purification. The YbhJ protein was partially purified to $50 \%$ purity by dyeaffinity chromatography as for PrpD except that $\mathrm{NaCl}(1 \mathrm{M})$ was used in the salt gradients. The protein eluted at $100-200 \mathrm{mM} \mathrm{NaCl}$ and purification was monitored solely by SDS-PAGE because no aconitase activity was associated with the enriched fractions.

PAGE, $\boldsymbol{M}_{\mathrm{r}}$ determination and other analytical procedures. PAGE was according to Laemmli (1970) using denaturing conditions $(0 \cdot 1 \%$ SDS and 10 or $15 \%$ acrylamide), or nondenaturing conditions (no SDS and $5-15 \%$ acrylamide). The $M_{r}$ of PrpD was deduced from denaturing SDS-PAGE, native gel mobilities, and gel filtration using a Sephacryl S200 HR column $(20 \times 330 \mathrm{mM})$ equilibrated and eluted with buffer A containing $1 \mathrm{M}$ citrate. The column was calibrated with standard proteins: $\beta$-amylase $\left(M_{\mathrm{r}} 200000\right)$, alcohol dehydrogenase (150000), bovine serum albumin (66000), carbonic anhydrase (29 000) and cytochrome $c(12400)$. The N-terminal amino acid sequences were determined by Edman degradation using an Applied Biosystems Protein Sequencer with samples from Coomassie-blue-stained electro-blots of SDS-PAGE gels. For Western blotting, samples containing $15 \mu \mathrm{g}$ protein fractionated by SDS-PAGE were transferred to Hybond C (Amersham) in a Bio-Rad Transblot Electrophoretic Transfer Cell and the blots were immuno-stained using polyclonal antisera according to Gruer et al. (1997b). Protein concentrations were determined by the Bio-Rad micro-assay procedure. Iron contents were assayed as described by Woodland \& Dalton (1984) and sulphur contents were assayed according to Beinert (1983).

DNA manipulation and methods. DNA was prepared and manipulated by standard procedures (Sambrook et al., 1989). Expression plasmids containing $y b h J$ and prpD were constructed by PCR-amplification of these genes from W3110 chromosomal DNA with the simultaneous incorporation of flanking NcoI and SalI restriction sites (underlined). The oligonucleotides used in the PCR amplification and cloning of $p r p D$ and $y b h J$ sequences were: $p r p D$ forward primer, GCGCACTTCACCATGGCAGATATCTGG; $p r p D$ reverse primer, GCCTTATCTGGTCGACAGATTCGATGCG; $y b b J$ forward primer, CTTTCTGCGCACTTCACCATGGCAGATATCTGGAGC; $y b b J$ reverse primer, GCCTTATCTGGTCGACAGATTCGATGCGATTCG. The PCR reactions each contained 200 ng template DNA, 100 pmol each primer and $1 \mathrm{U}$ Taq DNA polymerase (Promega). The major amplified product in each reaction was purified and cloned in ptac-85 (Marsh, 1986) as NcoI-SalI fragments. Plasmids from $\mathrm{Ap}^{\mathrm{R}}$ transformants of DH5 $\alpha$ were screened for inserts of the desired size and the constructions were confirmed by repeat PCR with the same primers followed by restriction digestion and DNA sequencing of the amplified products. Representative plasmids were designated pGS1575 (prpD $\left.D^{+}\right)$and pGS1576 $\left(y b h J^{+}\right)$and transferred to JRG3259. Synthesis of 
RNA and gel retardation analysis to determine mRNA binding properties was according to Tang \& Guest (1999).

Mutant construction. An acnA acnB ybhJ triple mutant was constructed by sequential P1vir-mediated transduction of $a c n A:: k a n^{\mathrm{R}}$ (from JRG2789) and $a c n B:$ tet $^{\mathrm{R}}$ (from JRG3258) into KS302, a strain that lacks the gal-ybhJ-bio region. The authenticity of the final mutant JRG4195 (acnA acnB $\Delta$ galbio) was confirmed by PCR with primers flanking the deletion. To provide an isogenic $y b h J^{+}$control strain, the gal-ybhJ-bio region was transferred from W3110 to JRG4195 by P1vir transduction and selection for $\mathrm{Gal}^{+} \mathrm{Bio}^{+}$colonies. Restoration of the wild-type gal-ybhJ-bio region was confirmed by nutritional tests for $\mathrm{Gal}^{+}$and $\mathrm{Bio}^{+}$and by DNA sequencing with a representative strain designated JRG4629. A prpD mutation was generated by direct linear DNA transformation of strain DY329 according to Yu et al. (2000). Two PCR primers containing $40 \mathrm{bp}$ prpD sequence and $20 \mathrm{bp} \mathrm{cam}^{\mathrm{R}}$ cassette (italic) were synthesized (forward primer ATGTCAGCTCAAATCAACAACATCCGCCCGGAATTTGATCATGGAGAAAAAAATCACTGG; reverse primer TTAAATGACGTACAGGTCGAGATACTCATTGACCGGCATCTTACGCCCCGCCCTGCCACT) and used with pACYC184 as template to amplify DNA molecules containing the entire $c^{\mathrm{R}}{ }^{\mathrm{R}}$ cassette flanked by $p r p D$ sequences. This amplified DNA promoted the replacement of $885 \mathrm{bp}(90 \%)$ of the chromosomal prpD gene by the $\operatorname{cam}^{\mathrm{R}}$ cassette in $\mathrm{Cm}^{\mathrm{R}}$ transformants of DY329. The location of the prpD::cam ${ }^{\mathrm{R}}$ lesion in a representative transformant (JRG4627) was confirmed by the size and restriction profile of the corresponding PCR-amplified segment of chromosomal DNA. The prpD:: cam $^{\mathrm{R}}$ lesion was then transferred to JRG3259 (acnA $a c n B$ ) by $\mathrm{P} 1$ vir-mediated transduction to generate the corresponding triple mutant, JRG4628 (acnA acnB prpD::cam ${ }^{\mathrm{R}}$ ), where the accuracy of the construction was reconfirmed by analysing the PCR-amplified DNA and sequencing across both prpD-cam junctions.

Materials. Samples of purified enzymes were kindly provided by Dr Y. Tang (E. coli aconitases, AcnA and AcnB) and Dr E. Ralph (Azotobacter vinelandii cysteine desulphurase, NifS). Porcine heart and Thermoplasma acidophilum citrate synthases were purchased from Sigma-Aldrich UK, as were acetylCoA, propionyl-CoA and substrates used in specificity tests.

\section{RESULTS}

\section{Partial purification and characterization of AcnC from E. coli JRG3259 (acnA::kan ${ }^{\mathrm{R}}$ acnB:: tet $\left.{ }^{\mathrm{R}}\right)$}

The starting point for this work was the observation that cell-free extracts of JRG3259 (acnA::kan ${ }^{\mathrm{R}}$ $\left.a c n B:: t^{\left(e t^{\mathrm{R}}\right.}\right)$, a strain that is totally deficient in AcnA and $A \operatorname{cn} B$, retained a low residual aconitase activity equivalent to approximately $5 \%$ of wild-type (Gruer et al., 1997b). The identity of the residual activity, designated AcnC, was first sought by purifying the enzyme from the double mutant. The AcnC activity, assayed routinely by measuring isocitrate dehydration, was found to be highest $\left[0.020 \mathrm{U}(\mathrm{mg} \text { protein })^{-1}\right]$ in cell-free extracts of early-stationary-phase aerobic L-broth cultures after an approximately twofold reactivation with $\mathrm{Fe}^{2+}$ under reducing conditions. Citrate served as an alternative substrate to isocitrate but in neither case was the product identified, and cis-aconitate was not hydrated, which is unusual for an aconitase. Attempts to isolate the protein(s) responsible for the AcnC activity were made by dye-affinity column chromatography, which had previously been used successfully for isolating AcnA and $\mathrm{AcnB}$ (see Methods). A typical AcnC purification is summarized in Table 2 and SDS-PAGE fractionation of samples taken at each stage is shown in Fig. 1(a). Major activity losses occurred during purification and the specific activity declined rather than increased. This was probably due to irreversible inactivation rather than loss of AcnC protein. A similar decline was observed previously in the purification of AcnB from an unamplified source, and it was attributed to oxidative degradation of the iron-sulphur cluster and the consequent lowering of the final specific activity by inactive but copurifying apo-enzyme (Bradbury et al., 1996). Although partially purified AcnC contained several polypeptides, one component $\left(M_{\mathrm{r}} 58000\right)$ had a fractionation pattern that matched the activity profile. Furthermore, Western blotting revealed that a component having the same mobility cross-reacted with anti-AcnA and anti-AcnB sera (Fig. 1a).

Fractions from the Procion Yellow column having the highest aconitase activities were pooled, concentrated and fractionated by SDS-PAGE and then transferred to PVDF membranes for $\mathrm{N}$-terminal amino acid sequence determination. One sequence (WGHPS) was detected and found to occur internally within two E. coli gene products: residues $112-116$ of the PrpD protein encoded by the prpRBCDE propionate utilization operon (accession no. P77243), and residues 101-106 of RluA, the ribosomal large subunit pseudouridine synthase A (accession no. P39219). The mass of the PrpD protein (predicted $M_{\mathrm{r}}$ 53952) is consistent with its comigration with (and possible contibution to) AcnC activity, which is associated with an $\mathrm{Acn} A \mathrm{~B}$ cross-reacting polypeptide of comparable size ( $M_{\mathrm{r}} 58000$ approx.). Also, because the second citrate synthase activity of $E$. coli has been shown to be a 2-methylcitrate synthase that functions in the 2-methylcitrate cycle of propionate catabolism (Textor et al., 1997; Gerike et al., 1998), the link with PrpD raised the possibility that the primary function of AcnC might be to convert 2-methylcitrate to 2-methylisocitrate in the 2-methylcitrate cycle. The detection of an internal PrpD sequence suggests that the samples recovered from SDS-PAGE were partially proteolysed before analysis, and it is interesting to note that the second citrate synthase was identified as 2-methylcitrate synthase $(\operatorname{PrpC})$ via an internal sequence (Gerike et al., 1998). Unfortunately, despite repeated attempts it proved impossible to isolate sufficient protein from JRG3259 to unequivocally identify the source of AcnC activity. Other strategies including database searching for potential AcnC candidates were therefore adopted.

\section{Sequence relationships between aconitase and two potential AcnC candidates}

Searching the complete E. coli genome (Blattner et al., 1997) revealed one potential AcnC candidate, YbhJ, encoded by a gene located in the $y b h D H I J-y b h C-$ att $\lambda-y b h B-b i o A$ region at $17 \cdot 4 \min (800 \mathrm{~kb})$ in the $E$. coli chromosome. The predicted YbhJ sequence (761 
Table 2. Typical purifications of AcnC and PrpD from E. coli

AcnC was purified from JRG3259, the $a c n A a c n B$ double mutant, and PrpD was purified from a transformant of JRG3259 containing the multicopy $p r p D^{+}$expression plasmid, pGS1575 (see Methods). In both cases, dye-affinity chromatography was used and one enzyme unit is defined as the amount required to dehydrate $1 \mu \mathrm{mol}$ isocitrate $\mathrm{min}^{-1}$ at $37^{\circ} \mathrm{C}$. The activities observed at each stage of the purification are those measured after treatment with $\mathrm{Fe}^{2+}$ and DTT, and the degree of enhancement afforded by the reactivation is shown in parentheses.

\begin{tabular}{|lccccc|}
\hline Purification step & $\begin{array}{c}\text { Total units (reactivation } \\
\text { factor) }\end{array}$ & $\begin{array}{c}\text { Total protein } \\
(\mathbf{m g})\end{array}$ & $\begin{array}{c}\text { Specific activity } \\
{\left[\mathbf{U}(\mathbf{m g} \text { protein })^{-1}\right]}\end{array}$ & $\begin{array}{c}\text { Yield }(\%) \\
\text { Purification } \\
\text { factor }\end{array}$ \\
\hline JRG3259 & & & $0 \cdot 020$ & 100 \\
Cell extract & $12 \cdot 0(2 \cdot 0)$ & 600 & $0 \cdot 009$ & 18 & $1 \cdot 0$ \\
Procion Red & $2 \cdot 14(1 \cdot 6)$ & 238 & $0 \cdot 005$ & $0 \cdot 45$ \\
Procion Yellow & $0 \cdot 28(2 \cdot 2)$ & 56 & $0 \cdot 056$ & 100 \\
JRG3259(pGS1575) & & & $0 \cdot 36$ & 27 \\
Cell extract & $450(12)$ & 800 & $0 \cdot 80$ & 18 \\
Procion Red & $120(11)$ & 325 & 102 & $6 \cdot 0$ \\
Procion Yellow & $82(10)$ & & & $14 \cdot 3$ \\
\hline
\end{tabular}

(a)

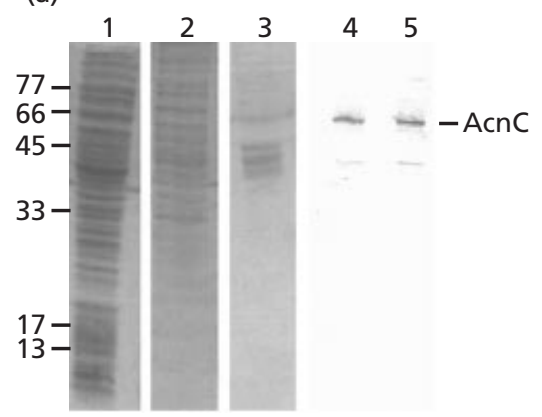

(b)

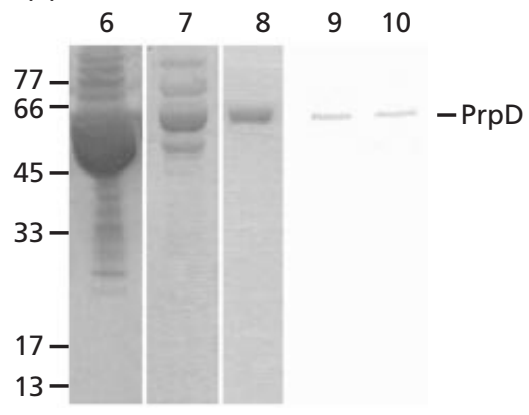

Fig. 1. Purification and Western blotting of AcnC. (a) Partial purification of AcnC from the unenriched source, JRG3259 $(a c n A a c n B)$. Coomassie-blue-stained SDS-PAGE (15\% gel) analysis showing active fractions at different stages of the purification: crude cell-free extract (lane 1); Procion Red column (lane 2); Procion Yellow column (lane 3). Western blot of Procion Yellow active fractions with anti-AcnA serum (lane 4) and anti-AcnB serum (lane 5). (b) Purification of PrpD from genetically enriched strain. Coomassie-blue-stained SDS-PAGE (15\% gel) analysis showing crude cell-free extract (lane 6), and active fractions from Procion Red column (lane 7) and Procion Yellow column (lane 8). Western blot of Procion Yellow active fractions with anti-AcnA serum (lane 9) and anti-AcnB serum (lane 10).

amino acids, $81505 \mathrm{Da}$ ) clearly indicated that $\mathrm{YbhJ}$ is a member of the aconitase protein family having the same domain organization as porcine mit-Acn and E. coli Acn A and sequence identities of $24 \%$ and $22 \%$, respectively (Fig. 2). Conservation of the three cysteine residues that serve as ligands for iron-sulphur clusters in Acn proteins indicated that $\mathrm{YbhJ}$ might likewise assemble such clusters. However, only 12 of the other 17 Acn active-site residues are conserved, suggesting that YbhJ may not exhibit aconitase activity although it could have a different catalytic specificity. The size predicted for YbhJ (81505 Da) is significantly smaller than typical aconitases and it is also considerably larger than the AcnAB cross-reacting component $\left(M_{\mathrm{r}} 58000\right.$ approx.) associated with the AcnC activity that was partially purified from JRG3259 (see above).

PrpD, the other potential AcnC candidate, was not detected by database searching. It is the product of the unidentified $\operatorname{pr} p D$ gene in the $\operatorname{pr} R B C D E$ operon located close to the lac operon at $7.5 \mathrm{~min}(350 \mathrm{~kb})$ in the E. coli chromosome. The PrpD protein was considered because the conversion of 2-methylcitrate to 2-methylisocitrate during propionate catabolism might involve an aconitase-like enzyme that retains some aconitase activity. This view is supported by the size of the $\mathrm{Acn} A B$ crossreacting polypeptide and the recovery of a PrpD sequence from fractions associated with AcnC activity (see above), and it was also strengthened by the enhancement of AcnC activity following growth in the presence of propionate (see below). However, the genederived amino acid sequence indicated that PrpD is not a member of the aconitase protein family. No sustained alignment between PrpD and any Acn or Acn structural domain was detected except for a region of $23 \%$ identity involving 151 residues in the $\mathrm{N}$-terminal segment of PrpD and part of the C-terminal domain of YbhJ (Fig. 2). Some short regions of remote similarity and uncertain 


$\begin{array}{lll}\text { Acn } & \text {. Por } & 1 \\ \text { AcnA } & \text {. Eco } & 1 \\ \text { YbhJ } & \text {. Eco } & 1 \\ & & \\ & & \\ & & \\ \text { Acn } & \text {. Por } & 60 \\ \text { AcnA } & \text {. Eco } & 73 \\ \text { YbhJ } & \text {. Eco } & 60 \\ \text { PrpD } & \text {. Eco } & 163 \\ & & \end{array}$

Acn . Por 122

AcnA. Eco 155

YbhJ .EcO 114

PrpD .Eco 284

Acn .Por 189 ACnA .ECO 236 YbhJ .Eco 180

Acn . Por 270 ACnA . Eco 317 YbhJ .Eco 262

Acn . Por 343 AcnA . EcO 396 YbhJ .ECO 328

Acn . Por 391 ACnA . Eco 478 YbhJ .Eco 397 PrpD .ECO 322

Acn . Por 464 AcnA .ECO 550 YbhJ .ECO 467

Acn . Por 536 ACnA . ECO 638 YbhJ .Eco 524

Acn .Por 591 ACnA. ECO 714 YbhJ .ECO 589 PrpD .ECO 58 PrpD .ECO 431

Acn. Por 660 AcnA .ECO 794 YbhJ .ECO 667

PrpD .ECO 123

Acn . Por 735

AcnA .Eco 872

YbhJ .ECO 743

PrpD .ECO 193

\section{$\vdash$ DOMAIN 1}

$\beta-\beta-\beta-\alpha \alpha \alpha \alpha \alpha \alpha \alpha \alpha \alpha \alpha \alpha \alpha \alpha \alpha--\alpha \alpha \alpha \alpha \alpha \alpha \alpha-\cdots \beta-\ldots \ldots$ QRAKVAMSHFEPHEYIRYDLLEKNIDIVRKRLNRPLTLSEKIVYG . . HLDDPANQEIERGK. . . . . . . MSSTLREASKDTLQAK. . . . . . . DKTYHYYSLPLAAKSL . GDITRLP . . KSLKVLLENLLRWQDGNSVTEEDIHALAGWLKN . MRRYLEHLMIKLSEK . . . . . . . GVFLASNNEIIAEEHFTGEIKKE . . EAKKGTIA . . . WSILSS . . . . . HNTSGNM. .

$\cdots \beta \beta \beta \beta \beta-\beta \beta \beta \beta \beta \alpha \alpha \alpha \alpha \alpha \alpha \alpha \alpha \alpha \alpha \alpha \alpha \alpha \alpha+\ldots \ldots \ldots+\beta \beta \beta \beta-\beta \ldots \ldots \alpha \alpha \alpha \alpha \alpha \alpha \alpha \alpha \alpha \alpha \alpha$ $\ldots$ TYLRLRPDRVAMQDATAQMAMLQFISSGLPKVAV . . . . . . . . PSTIHCDHLIEAQLGG . . . . EKDLRRAKDINQ AHADREIAYRPARVLMQDFTGVPAVVDLAAMREAVKRLGGDTAKVNPLSPVDLVIDHSVTVDRFGDDEAFEENVRLEMERNH $\ldots$. DKLKTKFDSIASHDITFVGIVOTAKASGMERF $\ldots \ldots \ldots \ldots$. . . . . PYVLTNCHNSLCAVGGT . . . . . . . . . . ING SFNRVGLDHVLLVKVAST

DH

$\alpha \alpha \alpha \alpha \alpha \alpha \alpha \alpha \alpha \alpha \alpha \alpha--\beta \beta \beta-\beta-\alpha \alpha \alpha \alpha \alpha \alpha \alpha \ldots \ldots \ldots \ldots \ldots-\beta \beta \beta \beta-\alpha \alpha \alpha \alpha \alpha \alpha \alpha \alpha \alpha-\beta \beta \beta \beta-\alpha \alpha \alpha \alpha \alpha \alpha$ EVYNFLATAGAKYG. VGFWRPGSGI IHQI ILEN . . . . . . . . . YAYPGVLLIGTDSHTPNGGGLGGICIGVGGADAVD ERYVFLKWGKOAFSRFSVVPPGTGICHOVNLEYLGKAVWSELODGEWIAYPD. TLVGTDSHTTMINGLGVLGWGVGGIEAEA DDHVFGLSAAORYG. GIFVPPHIAVIHOYMREM . . . . . . . . . . MAGGGKMILGSDSHTRY. GALGTMAVGEGGGELVK

H KISFPAEFHSQTAVEA DSH N

$\alpha \alpha \alpha-\beta \beta \beta \beta-\beta \beta \beta \beta \beta \beta \beta \beta-$ DOMAIN 2- $\alpha \alpha \alpha \alpha \alpha \alpha \alpha \alpha \alpha \alpha \alpha \alpha \alpha \alpha-\beta \beta \cdot-\beta \beta \beta \beta \beta-\alpha \alpha \alpha \alpha-\alpha \alpha \alpha \alpha \alpha \alpha \alpha \alpha \alpha \alpha-\beta \beta-\beta \beta$ $\alpha \alpha \alpha-\beta \beta \beta \beta-\beta \beta \beta \beta \beta \beta \beta \beta-\alpha \alpha \alpha \alpha \alpha \alpha \alpha \alpha \alpha \alpha \alpha \alpha \alpha \alpha-\beta \beta-\beta \beta \beta \beta \beta-\alpha \alpha \alpha \alpha-\alpha \alpha \alpha \alpha \alpha \alpha \alpha \alpha \alpha-\beta-\beta \beta-\beta \beta$ VMAGI PWELKCPKVIGVKLTGSLSGWTSPKDVILKVAGILTVKGGT. GAIVEYHGPGVDS ISCTGMATICNMGAEIGATTSV QLLNDTWDIDYPGVVAVHLTGKPAPYVGPQDVALA I I GAVFKNGYVKNKVMEFVGPGVSALSTDFRNSVDVMTTETTCLSSV

$\beta-\alpha \alpha \alpha \alpha \alpha \alpha \alpha \alpha \alpha-\alpha \alpha \alpha \alpha \alpha \alpha \alpha \alpha \alpha \alpha-\ldots \ldots \ldots-\beta \beta \beta \beta \beta \beta-1$ - DOMAIN 3- $\beta \beta \beta-\beta \beta \beta-\alpha \alpha \alpha \alpha \alpha \alpha \alpha \alpha$ FPYNHRMKKYLSKTGRADIA. NLADEF . . . . . KDHLVPDPGCHYDQVIEINLSELK. PHINGPFTPDLAHPVAEVGSVAE FPIDAVTLDYMRLSGRSEDQVELVEKYAKAQGMWRN . . . PGDEPIFTSTLELDMNDV. EASLAGPKRPQDRVALPDVPKAFA WQTDEEWHNWLALHGRGQDYCQLN . . . . . . . . . PQPMAYYDGCISVDLSAIK. PMIALPFHPSNVYEIDTLNQNLT

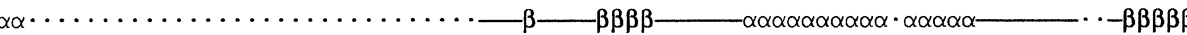
$\mathrm{KE} . \ldots \ldots \ldots \ldots \ldots \ldots$ GWPLDIRVGLIGSCTNSSYEDMGRSAAV. AKQALAHGLKCK. . SQFTIT AS. NELEVNATH . . . KDRQPV. DYVMNGHQYQLPDGAVVIAAITSCTNTSNPSVLMAAGLLAKKAVTLGLKRQPWVKASLA 477 DILREIEIESERVAHGKAKLSLLDKVENG . . . . . RLKVQQGIIAGCSGGNYENVIAAANALRGQSC. . . . . . GNDTFSLA 396 C

. $\beta \alpha \alpha \alpha \alpha \alpha \alpha \alpha \alpha \alpha-\alpha \alpha \alpha \alpha \alpha \alpha-\beta \beta \beta-\alpha \alpha \alpha-\beta-\cdots \cdots+-\beta \beta \beta \beta \beta-\beta \beta \beta \beta \beta$ .. PGSEQIRATIERDGYAQVLRDVGGIVLANACGPCIGQWDR . . . . . KDIKKGE. KNTIVTSYNRNFTGRNDANPETHAFV .. PGSKVVSDYLAKAKLTPYLDELGFNLVGYGCTTCIGNSGPLPDPIETAI KKGDLTVGAVLSGNRNFEGRIHPLVKTN. WI VYPSSOPVFMDLAKKGVVADLIGAGAI IRTAFCGPCFG. AGDTPINN . . . . $\ldots \ldots \ldots, \ldots$ GLSIRHTTRNFPNREGSKP. ANGO IRTHEACIRT IDKKGPLNNPAD DKFKINLARQFPTRQQQRI

$$
\text { C C }
$$$$
\text { RN R }
$$

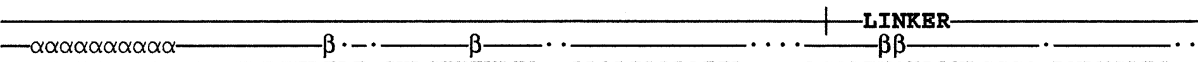
TSPEIVTALAIAGTLKFNPETDFLT . GKDGKKFKLEA. . PDADELPRAEFD. . . PGQDTYOHPPKDSSGQ . RVDVSPTS . ASPPLVVAYALAGNMNINLASEPIGHDRKGDPVYLKDIWPSAQEIARAVEQVSTEMFRKEYAEVFEGTAEWKGINVTRSDTY SAVALMDARSIAATAA . . NGGYLT . . . . . . SASELDCW . . . DNVPEYAFD . . . . VTPYKNR . VYQGFV . . KGATQ . . . . . .

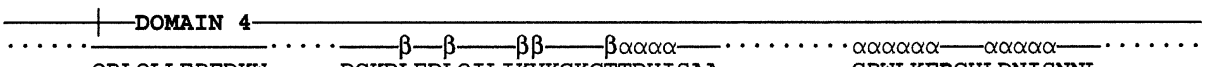
$\ldots \ldots$ QRLQLLEPFDKW . . . . DGKDLEDLQILIKVKGKCTTDHISAA . . . . . . GPWLKFRGHLDNISNNL . . . .

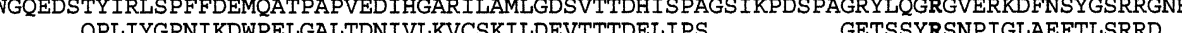
$\mathbf{R}$

$\cdots \cdots-\beta \beta-\cdots \cdot \beta \beta-\beta \beta-\beta \beta-\alpha \alpha \alpha \alpha \alpha \alpha \alpha \alpha \alpha \alpha-\cdots-\beta \beta \beta \beta-\beta \beta-\beta \beta-\alpha \alpha \alpha \alpha \alpha \alpha \alpha \alpha-\beta \beta-\beta$ $\ldots . .$. LIGATNIENR ..... KANSVRNAVTOEFGPVPDTARYYKOH . . GIRWVVIGDENYGEGSSREHRALEPRHLGGRAI EVMMRGTFANIRIRNEMVPGVEGGMTRHLPDSDVVSIYDAAMRYKOE . OTPLAVIAGKEYGSGSSRDWAAKGPRLLGIRVV PGYVSRSKATAELENQRLAGNVSELTEVFARIKQIAGQEH. IDPLQT . . EIGSMVYAVKP. GDGSAREQAASCQRVIGGLAN KKLLGPIVPGTVVPNGVRVPGTQFQ. LDPVQAAFEIGAMIRWLDF. NDTWLAAEWGHPSDNLGGILA EYPIGHARRRQEIP

SSR

$\beta \beta-\beta-\cdot \alpha \alpha \alpha \alpha \alpha \alpha \alpha \alpha \alpha-\beta \beta \beta \beta \beta-\alpha \alpha \alpha \alpha \alpha \alpha-\cdots-\beta \beta \beta \beta \beta-\cdots \frac{\beta}{\beta} \cdot \frac{\beta \beta \beta \beta \beta-}{\beta \beta \beta \beta \beta-} \cdot \alpha \alpha$ TTKSFA RIHETNLKKQGLLPLTFADPADYNKI . . HPVDKLTIQGLK. . DFAPGKPLKCIIKHPNG . TQETILLNHTFN .ET IAESFE RIHRSNLIGMGILPLEFPQGVTRKTLGLTGEEKIDIGDLQ . . NLQPGATVPVTLTRADG. SQEVVPCRCRIDTAT IAEEYATKRYRSNVINWGMLPLQMAE. VPTFEVG . . . DYIYIPGIKAALDNPGTTFKGYVIHEDAPVTEITLYMESL. TAE TADWLSR . . . . . NAVASGKAPLTMRR . VLTAMIK. . . . AH . EIQGCIALENSFNRVGLDHVLLVKVASTAVVAEMLGL . TRE

Fig. 2. For legend see facing page. 
(a)

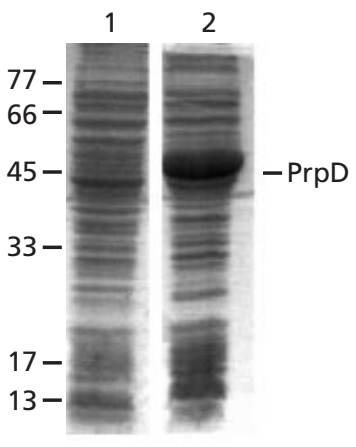

(b)

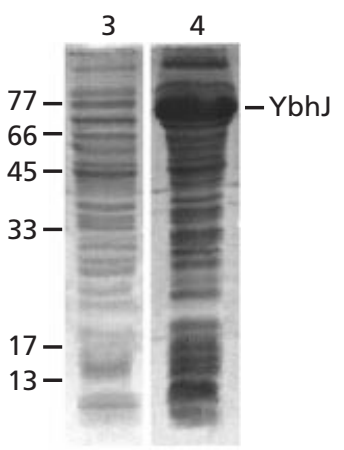

Fig. 3. Overproduction of PrpD and YbhJ. Coomassie-bluestained SDS-PAGE (15\% gel) showing cell-free extracts of transformants of JRG3259 containing prpD and ybhJ expression plasmids grown for $8 \mathrm{~h}$ in $\mathrm{L}$ broth plus ampicillin and induced with IPTG (30 $\mathrm{mg} \mathrm{I}^{-1}$ ) after $1 \mathrm{~h}$, when present. (a) Transformants containing ptac-85 prpD $D^{+}$grown without IPTG (lane 1) and with IPTG (lane 2). (b) Transformants containing pGS1576 (ptac-85 $y b h J^{+}$) grown without IPTG (lane 3) and with IPTG (lane 4).

significance were detected in regions corresponding to each of the four structural domains of porcine Acn and E. coli AcnA (not shown in Fig. 2), but five PrpD segments containing residues that might correspond to active-site residues in aconitase are shown in Fig. 2. These residues include one of six cysteine residues that are potential iron-sulphur cluster ligands in $\operatorname{PrpD}$, six residues that are fully conserved, and three that are conservatively substituted relative to aconitase. Similar

analyses failed to detect any sustained alignment of PrpD with other potentially related E. coli enzymes including the three fumarases (A, B and C) and dihydroxy-acid dehydratase. Indeed no sustained similarities were observed with any other database sequences of known function, although PrpD orthologues are known to occur in Salmonella typhimurium and other species (Horswill \& Escalante-Semerena, 1997).

\section{Overexpression and inactivation of AcnC candidates (PrpD and YbhJ)}

To establish whether either of the AcnC candidates (PrpD and $\mathrm{YbhJ}$ ) contribute to the residual aconitase activity in JRG3259 (acnA $a c n B$ ) the effects both of overexpressing and inactivating the $\operatorname{prpD}$ and $y b h \mathrm{~J}$ genes on the AcnC activities of AcnAB-null strains were investigated. The relevant coding regions were PCRamplified and cloned in ptac-85 to generate two expression plasmids, pGS1575 (ptac-85 prpD $^{+}$) and pGS1576 (ptac-85 $y b h J^{+}$); see Methods. The protein profiles confirmed that the synthesis of both proteins in transformants of JRG3259 is greatly enhanced by IPTG (Fig. 3). Enzymological tests with IPTG-induced transformants of DH5 $\alpha$ and JRG3259 further showed that prpD $\mathrm{D}^{+}$overexpression increased the combined aconitase and AcnC activities of the $\mathrm{Acn}^{+}$host by $35-42 \%$ and the AcnC activity of the AcnAB-null host by $\sim 26$-fold, whereas $y b \mathrm{bJ}^{+}$overexpression had no significant effect in either host (Table 3). These results supported the view that PrpD might be responsible for the AcnC activity in JRG3259, but PrpD overproduction would not complement the growth phenotype of the AcnAB-null strain.

Table 3. Effects of overproducing PrpD and YbhJ on the aconitase activities of wild-type and AcnAB-deficient hosts

The prpD and $y b h J$ genes were overexpressed in E. coli DH5 $\alpha\left(a c n A^{+} a c n B^{+}\right)$and JRG3259 (acnA $a c n B)$. Cell-free extracts were prepared from aerobic cultures grown for $8 \mathrm{~h}$ in $\mathrm{L}$ broth containing ampicillin (100 $\left.\mathrm{mg} \mathrm{l}^{-1}\right)$ to maintain the plasmids, pGS1576 $\left(y b h J^{+}\right)$and pGS1575 $\left(p r p D^{+}\right)$, with IPTG $\left(30 \mathrm{mg} \mathrm{l}^{-1}\right)$ added after $1 \mathrm{~h}$ to induce expression from the tac promoters. The combined aconitase and $\mathrm{AcnC}$ activities were assayed in triplicate by measuring isocitrate dehydration in cell-free extracts treated with $\mathrm{Fe}^{2+}$ and DTT.

\begin{tabular}{|c|c|c|}
\hline \multirow[t]{2}{*}{ Expression plasmid } & \multicolumn{2}{|c|}{$\begin{array}{c}\text { Enzyme activity }\left[\mathrm{U}(\mathrm{mg} \text { protein })^{-1}\right] \text { after induction of } \\
\text { transformants of: }\end{array}$} \\
\hline & $\mathrm{DH} 5 \alpha\left(\operatorname{acn} A^{+} a c n B^{+}\right)$ & JRG3259 (acn $A$ acnB $)$ \\
\hline None & $0 \cdot 58 \pm 0 \cdot 04$ & $0 \cdot 018 \pm 0 \cdot 002$ \\
\hline ptac- 85 & $0 \cdot 55 \pm 0 \cdot 04$ & $0 \cdot 018 \pm 0 \cdot 002$ \\
\hline pGS1575 (prpD $\left.D^{+}\right)$ & $0 \cdot 78 \pm 0.05$ & $0 \cdot 480 \pm 0 \cdot 040$ \\
\hline pGS1576 $\left(y b h J^{+}\right)$ & $0 \cdot 56 \pm 0 \cdot 05$ & $0 \cdot 020 \pm 0 \cdot 002$ \\
\hline
\end{tabular}

Fig. 2. Multiple amino acid sequence alignment for porcine heart mitochondrial aconitase (Acn) and $E$. coli aconitase $A$ (AcnA) with the gene-derived YbhJ sequence and segments of the PrpD sequence. The structural domains, $\alpha$-helices $(\alpha)$, $\beta$-strands $(\beta)$ and random coils $(-)$ of porcine Acn are shown above the alignment and insertion-deletions are denoted by dots. Conservation of the three cysteine residues that bind the [4Fe-4S] cluster and a further 17 active-site residues (inserted beneath the alignment) are indicated in bold-face. One large segment of PrpD that is significantly related to YbhJ is indicated, as are isolated regions of PrpD containing potential active-site residues equivalent to those in Acns. 
However, because it was not possible to ascertain whether pGS1576 expresses an active YbhJ protein, an acnA acnB ybhJ triple mutant (JRG4195) was constructed to see whether the residual aconitase activity of an $a c n A B$ double mutant is lowered by $y b h \mathrm{~J}$ inactivation. The triple mutant was constructed by sequentially transducing the $a c n A:: k a n^{\mathrm{R}}$ and $a c n B:: t^{\mathrm{R}}{ }^{\mathrm{R}}$ lesions into KS302, which already lacks the $y b h J$ gene by virtue of its gal-bio deletion (see Methods). A wild-type gal-bio region was also transduced back into the triple mutant (JRG4195) in order to create an isogenic acnA $a c n B$ double mutant (designated JRG4629) to facilitate direct enzymological comparisons. These showed that the aconitase activities of the strains were not significantly affected by the state of the chromosomal $y b \mathrm{hJ}$ gene: 0.024 U (mg protein) ${ }^{-1}$ for JRG4195 (acnA acnA $y b h J)$ compared to $0.026 \mathrm{U}$ (mg protein) ${ }^{-1}$ for JRG4629 $(a c n A a c n B)$. It was therefore concluded that the YbhJ protein is not a source of AcnC activity.

Inactivation of $\operatorname{PrpD}$ was achieved by constructing a prpD:: cam $^{\mathrm{R}}$ derivative of JRG3259 (acnA acnB) designated JRG4628 (acnA acnB prpD:: cam ${ }^{\mathrm{R}}$ ) in which most of the chromosomal $p r p D$ gene is replaced by a $c a m^{\mathrm{R}}$ cassette; see Methods. The aconitase specific activities in cell-free extracts of the double mutant, $0.020 \mathrm{U}(\mathrm{mg}$ protein $)^{-1}$, were lowered to $0.002 \mathrm{U}$ (mg protein $)^{-1}$ in the triple mutant, indicating that disruption of the $p r p D$ gene virtually eliminates the residual aconitase activity (AcnC) of the AcnAB-null strain. These observations strongly indicate that $\operatorname{PrpD}$ is the major source (and probably the sole source) of AcnC activity. It is also relevant to note that growing the AcnAB-null strain in the presence of added propionate $(10-50 \mathrm{mM})$ increased the AcnC activity by up to $1 \cdot 8$-fold $[0.036 \mathrm{U}$ (mg protein) $)^{-1}$ with $40 \mathrm{mM}$ propionate]. However, propionate was not normally added to growth media, so that the AcnC activity would not be masked or otherwise affected by specific propionate-inducible enzymes.

\section{Purification, properties and metabolic function of PrpD}

Although attempts to purify AcnC from an unamplified source (JRG3259; acnA $a c n B$ ) failed to identify the enzyme unequivocally, they did provide valuable clues leading to the conclusion that PrpD is the source of AcnC activity. Further studies on PrpD were made with protein purified from a strain containing the $\operatorname{prpD}$ expression plasmid (pGS1575) in an AcnAB-null host (JRG3259). A typical purification producing PrpD protein that was judged to be $97 \%$ pure by quantitative densitometry (Fig. 1b), with a yield of $32 \mathrm{mg}$ per litre of culture, is outlined in Table 2. No decline in specific activity was observed, presumably because inactivated enzyme represents a much smaller proportion of the total protein recovered from the highly enriched starting material. The N-terminal amino acid sequence of the purified protein, XAQINNIRPEFD, was identical to that predicted for PrpD assuming that the unidentified residue $(\mathrm{X})$ is serine and the initiating formylmethionine
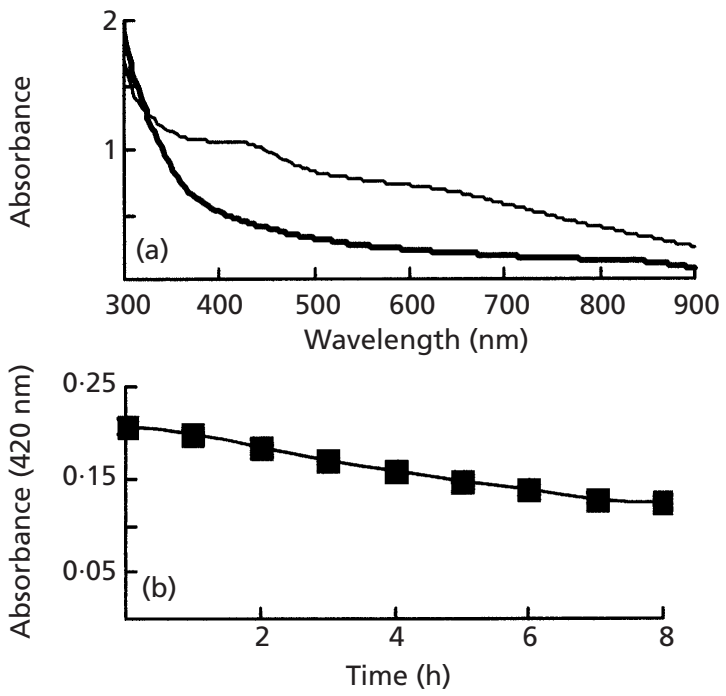

Fig. 4. Optical properties of PrpD. (a) Iron-sulphur clusters were reconstituted anaerobically at $25^{\circ} \mathrm{C}$ in purified PrpD protein $(13 \mathrm{nmol})$ using the NifS-mediated procedure; see Methods. The panel shows the $300-900 \mathrm{~nm}$ regions of the optical spectra obtained for the starting material (thick line) and for the sample after $3 \mathrm{~h}$ (thin line). (b) Stability of PrpD iron-sulphur clusters. A sample of PrpD protein having an $A_{420}$ of 0.07 at $420 \mathrm{~nm}$ was reconstituted by the NifS-mediated procedure until there was no further increase in absorbance. It was then exposed to air by removing the cap from the cuvette at zero time and the subsequent decrease in absorbance was monitored for a further $8 \mathrm{~h}$.

residue is removed post-translationally. The purified PrpD protein cross-reacted strongly with anti-AcnA and anti-AcnB sera (Fig. 1b), providing further evidence to suggest that the cross-reacting component in the AcnC partially purified from the unamplified source is PrpD (Fig. 1a). Gel filtration and native gel electrophoresis indicated that purified $\operatorname{PrpD}$ is a monomeric protein of $M_{\mathrm{r}}$ approximately 54000, which is consistent with the predicted $M_{\mathrm{r}}$ of 53821 for the 482-residue protein lacking the $\mathrm{N}$-terminal methionine residue. The AcnClike activity of PrpD exhibited the same $\mathrm{pH}$ profile (optimum range $7 \cdot 0-8 \cdot 0$ ), stability (half-life of $30 \mathrm{~min}$ at $50^{\circ} \mathrm{C}$ ) and failure to use cis-aconitate as a substrate (see below), as the AcnC of cell-free extracts of the AcnABnull strain (data not shown). As isolated, purified PrpD contained up to 1.26 atoms of iron and 1.4 atoms of acidlabile sulphur per monomer but very little activity, and after treatment with $\mathrm{Fe}^{2+}$ and DTT these values rose to 2.5 and 1.8 (respectively) and activity was restored, suggesting that PrpD contains an iron-sulphur cluster that is essential for maximum activity. Reconstitution of the iron-sulphur cluster was monitored spectrophotometrically under anaerobic conditions using cysteine desulphurase (NifS) as the sulphide generator (see Methods). As shown in Fig. 4(a), the spectrum acquired a broad absorbance band around $420 \mathrm{~nm}$. After removing excess iron and sulphur under anaerobic conditions, the respective iron and acid-labile sulphur contents were 2.3 and 1.8 atoms per monomer. On exposure 
Aconitase assays were performed in triplicate with a variety of potential substrates using purified PrpD and cell extracts of aconitase-deficient mutants, JRG3259 (acnA acnB prpD ${ }^{+}$) and JRG4628 ( $a c n A$ acnB prpD) after treatment with $\mathrm{Fe}^{2+}$ and DTT. One enzyme unit catalyses the dehydration/hydration of $1 \mu \mathrm{mol}$ of isocitrate/cis-aconitate or equivalent substrates $\min ^{-1}$ at $37^{\circ} \mathrm{C}$. The molar absorption coefficient for cis-aconitate was applied throughout, a 'no-substrate' activity of $<0.002 \mathrm{U}$ (mg protein $)^{-1}$ was subtracted, and unless shown the standard deviations were less than $\pm 2 \%$. The asterisks $(*)$ denote that the substrates, citrate and 2-methylcitrate, were generated enzymically by pre-incubating oxaloacetate and either propionyl-CoA or acetyl-CoA with citrate synthase (see Methods).

\begin{tabular}{|c|c|c|}
\hline Enzyme source & Substrate & $\begin{array}{l}\text { Enzyme activity } \\
{\left[\mathrm{U}(\mathrm{mg} \text { protein })^{-1}\right]}\end{array}$ \\
\hline \multirow[t]{17}{*}{ PrpD } & Citrate & $0 \cdot 89$ \\
\hline & DL-Isocitrate & 0.78 \\
\hline & D-Tartrate & $0 \cdot 12$ \\
\hline & L-Tartrate & $0 \cdot 35$ \\
\hline & meso-Tartrate & $0 \cdot 40$ \\
\hline & D-Malate & $0 \cdot 33$ \\
\hline & L-Malate & $0 \cdot 27$ \\
\hline & DL-Citramalate & $0 \cdot 61$ \\
\hline & 2-Methylcitrate* & $1 \cdot 65$ \\
\hline & Citrate $^{*}$ & $0 \cdot 82$ \\
\hline & cis-Aconitate & $<0 \cdot 001$ \\
\hline & trans-Aconitate & $<0.001$ \\
\hline & Fumarate & $<0.002$ \\
\hline & Maleate & $<0.001$ \\
\hline & Mesaconate & $<0.002$ \\
\hline & Citraconate & $<0 \cdot 001$ \\
\hline & Itaconate & $<0 \cdot 001$ \\
\hline \multirow[t]{2}{*}{ JRG3259 (acnAB prpD $\left.D^{+}\right)$} & 2-Methylcitrate* & $0 \cdot 030 \pm 0 \cdot 008$ \\
\hline & Citrate* & $0.018 \pm 0.006$ \\
\hline \multirow[t]{2}{*}{ JRG4628 (acnAB prpD) } & 2-Methylcitrate* & $0 \cdot 001 \pm 0 \cdot 001$ \\
\hline & Citrate* & $0 \cdot 001 \pm 0 \cdot 001$ \\
\hline
\end{tabular}

to air the $420 \mathrm{~nm}$ absorbance declined steadily over an $8 \mathrm{~h}$ period (Fig. $4 \mathrm{~b}$ ) indicating that the iron-sulphur clusters are unstable under aerobic conditions. It was therefore concluded that PrpD can acquire one [2Fe-2S] cluster per monomer, which is essential for maximum catalytic activity.

The E. coli AcnA and AcnB apo-proteins have been shown to function as specific RNA-binding proteins that regulate translation of both acn-mRNAs (Tang \& Guest, 1999). However, comparable tests with unreactivated PrpD failed to detect any interaction with either acnA-mRNA or $a c n B-m R N A$. This is probably not surprising in view of the lack of homology between PrpD and the Acn proteins.

The $\operatorname{prpD}$ gene, like other genes in the $\operatorname{pr} p R B C D E$ operon, has been shown to be required for propionate catabolism via the methylcitrate cycle in S. typhimurium (Horswill \& Escalante-Semerena, 1999a, b). The E. coli genome possesses an analogous prp operon but E. coli cannot use propionate as a sole carbon source without prior adaptation, possibly involving one or more uniden- tified mutations. Nevertheless, the $p r p B$ and $p r p C$ genes have been shown to encode two functional enzymes, 2-methylisocitrate lyase and 2-methylcitrate synthase, respectively (Textor et al., 1997; Gerike et al., 1998; Brock et al., 2001). It has been further suggested that prpD might encode a methylaconitase, primarily because of its location in the prp operon and the known functions of the neighbouring genes (Horswill \& Escalante-Semerena, 1999a, b; Brock et al., 2001). Here, the substrate specificity of purified and reactivated E. coli PrpD was tested using a range of potential substrates including 2-methylcitrate (Table 4). The latter was synthesized by preincubating propionyl-CoA and oxaloacetate with citrate synthase but not purified or subjected to isomer analysis (see Methods). The results showed that $\operatorname{PrpD}$ is capable of introducing a double bond into all nine of the hydroxyacids tested (Table 4). Moreover, 2-methylcitrate proved to be a better substrate than citrate and citrate generated enzymically in directly comparable control reactions. This is consistent with the possibility that 2-methylcitrate is the primary substrate for PrpD. The preference for 2-methylcitrate 
Table 5. Specific activities of purified enzymes with enzymically synthesized substrates (citrate, 2-methylcitrate and 2-methyl-cis-aconitate)

Substrates, including 2-methyl-cis-aconitate (assumed to be the product of sequential citrate synthase and PrpD activities) were generated enzymically in preliminary reactions (see Methods). Aconitase and aconitase-like activities of purified enzymes were assayed in triplicate after treatment with $\mathrm{Fe}^{2+}$ and DTT, and expressed as aconitase equivalents, where one unit catalyses the dehydration or hydration of $1 \mu \mathrm{mol}$ of the substrate $\min ^{-1}$ at $37^{\circ} \mathrm{C}$, using the molar absorption coefficient for cis-aconitate. Values of $\leqslant 0.002 \mathrm{U}$ (mg protein) ${ }^{-1}$ obtained in controls lacking oxaloacetate, acetyl-CoA or propionyl-CoA in the initial reaction have been subtracted. The amounts of enzyme added per $1 \mathrm{ml}$ reaction were: $\operatorname{PrpD}, 0.07 \mathrm{mg}(0.06 \mathrm{U})$; AcnA, 0.12 mg $(0 \cdot 1 \mathrm{U}) ; \mathrm{AcnB}, 0.08 \mathrm{mg}(0 \cdot 1 \mathrm{U})$; and YbhJ, $0.04 \mathrm{mg}$ protein (50\% pure).

\begin{tabular}{|lcc|}
\hline Substrate & $\begin{array}{c}\text { Source of } \\
\text { enzyme }\end{array}$ & $\begin{array}{c}\text { Enzyme activity } \\
{\left[\mathbf{U}(\mathbf{m g} \text { protein })^{-1}\right]}\end{array}$ \\
\hline Citrate & PrpD & $0 \cdot 88 \pm 0 \cdot 08$ \\
Citrate & AcnA & $3 \cdot 24 \pm 0 \cdot 15$ \\
Citrate & AcnB & $3 \cdot 60 \pm 0 \cdot 12$ \\
Citrate & YbhJ & $<0 \cdot 001$ \\
2-Methylcitrate & PrpD & $1 \cdot 64 \pm 0 \cdot 17$ \\
2-Methylcitrate & AcnA & $0 \cdot 01 \pm 0 \cdot 005$ \\
2-Methylcitrate & AcnB & $0 \cdot 01 \pm 0 \cdot 004$ \\
2-Methylcitrate & YbhJ & $<0 \cdot 001$ \\
2-Methyl-cis-aconitate & AcnA & $0 \cdot 002 \pm 0 \cdot 001$ \\
2-Methyl-cis-aconitate & AcnB & $0 \cdot 002 \pm 0 \cdot 001^{*}$ \\
2-Methyl-cis-aconitate & YbhJ & $0 \cdot 006 \pm 0 \cdot 001^{*}$ \\
\hline
\end{tabular}

* Activities with authentic cis-aconitate under comparable conditions were $0 \cdot 20 \mathrm{U}$ (mg protein $)^{-1}$ for AcnA and AcnB.

relative to citrate was also exhibited by cell-free extracts of the AcnAB-null mutant, JRG3259 (Table 4). In addition it was observed that activity with both citrate and 2-methylcitrate was abolished by the prpD lesion of JRG4628 (acnA acnB prpD). These observations further confirm that the AcnC activity of the $\operatorname{acn} A B$ double mutant is due to the broad substrate specificity of PrpD and its consequent ability to dehydrate citrate and isocitrate as well as 2-methylcitrate.

In marked contrast, the broad specificity of PrpD for hydroxyacids did not extend to substrates containing double bonds: none of seven such substrates, including cis-aconitate, was hydrated (Table 4). Indeed, it appeared that unlike typical aconitases, PrpD functions solely as a dehydratase and not as a hydratase. Other experiments confirmed that PrpD lacks the ability to catalyse the reversible isomerization of citrate and isocitrate even though it can dehydrate both substrates. For example, it was predicted that if PrpD could function as an aconitase, overproduction of PrpD might relieve the glutamate auxotrophy of JRG3259 (acnA $a c n B)$ on glucose minimal medium (Gruer et al., 1997b). The AcnAB-null mutant normally shows a weak response to glutamate before being overgrown by faster-growing derivatives that have acquired a citrate synthase mutation $(g l t A)$ and with it an obligatory requirement for glutamate (Lakshmi \& Helling, 1976; Gruer et al., 1997b). However, IPTG-mediated amplification of PrpD synthesis in pGS1575 transformants of JRG3259 (shown to retain an active citrate synthase) failed to complement the $\mathrm{Glt}^{-}$phenotype. Plasmid-mediated amplification of PrpD likewise failed to reverse the acetate-utilization defect (Aut ${ }^{-}$phenotype) of the AcnAB-null strain. It was thus concluded that neither the anabolic nor the catabolic functions of the citric acid cycle that are normally supported by aconitase can be satisfied by $\operatorname{PrpD}(\mathrm{AcnC})$. Analogous experiments showed that the $\mathrm{Glt}^{-}$and $\mathrm{Aut}^{-}$phenotypes of the AcnAB-null strain (JRG3259) could not be complemented by the ybhJ expression plasmid (pGS1576), with or without IPTG.

\section{Related observations with AcnA, AcnB and YbhJ}

In reciprocal substrate specificity studies, AcnA and $A c n B$ were tested for their ability to use enzymically generated citrate, 2-methylcitrate and 2-methyl-cisaconitate, assuming that the latter is the product of sequential citrate synthase and PrpD preincubations and that the reactions are not impaired by other materials in the unpurified substrate (Table 5). The two aconitases were at least three times more active than PrpD with citrate as substrate but their activities with 2-methylcitrate were very low $(0 \cdot 6 \%$ of the activity observed with $\operatorname{PrpD})$, and activities with 2-methyl-cis-aconitate also very low $(1.0 \%$ of the rates obtained with comparable amounts of cis-aconitate). In parallel studies with the YbhJ protein purified to $50 \%$ homogeneity from induced cultures of JRG3259(pGS1576), no aconitase activity $(<0.001 \mathrm{U}$ per mg protein) was detected with enzymically synthesized citrate and 2-methylcitrate (Table 5). A weak hydratase activity was observed with 2-methyl-cis-aconitate, but the possibility that this might be due to a contaminating protein cannot be excluded.

\section{DISCUSSION}

The results clearly showed that PrpD, an enzyme encoded by the propionate-catabolic operon (prp $R B C D E)$, is responsible for the residual aconitase activity (AcnC) of the AcnAB-null strain. Specificity studies with the purified enzyme further indicated that PrpD is a 2-methylcitrate dehydratase rather than an aconitase. It definitely lacks overall aconitase activity because even though citrate and isocitrate were dehydrated, cis-aconitate was not hydrated, nor would PrpD overproduction complement the growth phenotype of the AcnAB-null strain. Nevertheless, there still remains the formal possibility that $\operatorname{PrpD}$ functions as a 2methylaconitase with the natural substrate because the enzyme was not tested with pure samples of each of the four stereoisomers of 2-methylcitrate or the corresponding products (see below). The sequence comparisons clearly indicated that PrpD is not related to members of the aconitase family (Fig. 2). Indeed, it is surprising that PrpD cross-reacted with two anti-Acn sera (Fig. 1). 


\author{
Propionate $+\mathrm{CoA}+\mathrm{ATP} \rightarrow$ Propionyl-CoA + ADP/AMP \\ Propionyl-CoA + Oxaloacetate $\rightarrow$ 2-Methylcitrate \\ 2-Methylcitrate $\rightarrow$ 2-Methylcis-aconitate $+\mathrm{H}_{2} \mathrm{O}$ \\ 2-Methylcis-aconitate $+\mathrm{H}_{2} \mathrm{O} \rightarrow$ 2-Methylisocitrate \\ 2-Methylisocitrate $\rightarrow$ Pyruvate + Succinate \\ Succinate $+\mathrm{FAD}+\mathrm{NAD} \rightarrow$ Oxaloacetate $+\mathrm{FADH}_{2}+\mathrm{NADH}_{2}$ \\ Propionate $+\mathrm{ATP}+\mathrm{FAD}+\mathrm{NAD} \rightarrow$ Pyruvate $+\mathrm{ADP} / \mathrm{AMP}+\mathrm{FADH}_{2}+\mathrm{NADH}_{2}$
}

\begin{abstract}
Fig. 5. Proposed reactions for propionate catabolism via the methylcitrate cycle. The enzymes are encoded by the prpRBCDE operon as follows: PrpE, propionyl-CoA synthetase; PrpC, 2-methylcitrate synthase; PrpD, 2-methylcitrate dehydratase/AcnC; ?, unidentified enzyme, Acn, YbhJ or even PrpD; PrpB, 2-methylisocitrate lyase; CAC, citric acid cycle enzymes (succinate dehydrogenase, fumarase and malate dehydrogenase). Based on studies with $S$. typhimurium and other organisms by Horswill \& EscalanteSemerena (1997, 1999a, b, 2001), Textor et al. (1997), Brock et al. (2001) and Gerike et al. (1998).
\end{abstract}

Unless these proteins share some small immunogenic motifs the most plausible explanation is that the early preparations of AcnA and AcnB used to raise antisera were contaminated by PrpD. Under appropriate conditions, isolated $\operatorname{PrpD}$ assembled a relatively unstable [2Fe-2S] cluster which was essential for maximum dehydratase activity. Spinach dihydroxy acid dehydratase is the best-characterized dehydratase containing a [2Fe-2S] cluster (Flint \& Emptage, 1988), but its amino acid sequence is not known and cannot therefore be compared with PrpD. Other potentially related enzymes such as the class I fumarases (FumA and FumB) of E. coli that were first identified by their genes and later shown to contain unstable [4Fe-4S] clusters (Bell et al., 1989; Flint et al., 1992) are not similar, nor does the pattern of cysteine residues in PrpD conform to that of any recognized iron-sulphur protein.

Amplified and partially purified preparations of the other potential source of AcnC activity, YbhJ, lacked aconitase activity and $y b h J$ deletion had no significant effect on the AcnC activity of the AcnAB-null strain. The YbhJ sequence clearly indicated that it is a member of the aconitase protein family with $15 / 20$ active-site residues conserved (including the three iron-liganding cysteine residues) and $22 \%$ sequence identity to AcnA. It may also be significant that the domain 4 region of $\mathrm{YbhJ}$ is remotely related to part of PrpD, but further work will be needed to identify the function of YbhJ.

The 2-methylcitrate dehydratase gene $(p r p D)$ is located in the E. coli propionate operon, which is directly related to the prpRBCDE operon of S. typhimurium that has been extensively characterized by Horswill \& Escalante-Semerena (1997, 1999a, b, 2001). In S. typhimurium LT2 the prp genes encode a transcriptional activator and four enzymes of the 2-methylcitrate cycle that permit growth on propionate as a sole carbon and energy source by catalysing its conversion to pyruvate as shown in Fig. 5. Propionate is an extremely poor substrate for E. coli K-12 but the pathway is induced for the degradation or co-metabolism of propionate (Textor et al., 1997). Since the present work was completed, Escalante-Semerena and co-workers have established that the PrpD protein of S. typhimurium is a 2- methylcitrate dehydratase and $\operatorname{PrpB}$ is a 2-methylisocitrate lyase (Horswill \& Escalante-Semerena, 2001); see Fig. 5. They also demonstrated that AcnA and AcnB can hydrate 2-methyl-cis-aconitate to 2-methylisocitrate, and have thus been able to reconstruct the conversion of propionate to pyruvate by the 2-methylcitrate pathway in vitro, using purified Prp and Acn enzymes. They further claimed that this route operates in vivo because studies with an acnA and $a c n B$ double mutant showed that aconitase enzymes are essential for propionate catabolism. This is an interesting possibility but since it is likely that aconitase is required for growth on pyruvate (as has been demonstrated in E. coli; Gruer et al., 1997b), aconitase cannot yet be unequivocally assigned to the hydration of 2-methyl-cis-aconitate in vivo.

The hexahistidine-tagged PrpD protein $\left(\mathrm{H}_{6} \operatorname{PrpD}\right)$ from S. typhimurium and the PrpD protein of E. coli are both 2-methylcitrate dehydratases that appear to lack aconitase activity, but they are remarkably different in other respects, despite being $94 \%$ identical at the primary structural level. Firstly, the S. typhimurium enzyme had no cofactor requirements nor was activity enhanced by iron, and it failed to acquire iron-sulphur clusters under reconstitution conditions (Horswill \& Escalante-Semerena, 2001), whereas the E. coli enzyme required treatment with iron and DTT for maximum activity. This discrepancy is difficult to explain unless the hexahistidine tag simultaneously prevents cluster acquisition and induces a cofactor-independent catalytic activity, possibly by enhancing protein-protein interactions. Alternatively, an active conformation might be restored to inactivated PrpD by the adventitious incorporation of an iron-sulphur cluster that is otherwise non-essential. In $E$. coli the reversible hydration of fumarate is catalysed by two enzymes that contain essential ironsulphur clusters (FumA and FumB) and one that lacks such cofactors (FumC), but in this case the primary and tertiary structures of the two classes of enzyme are very different (Miles \& Guest, 1984; Woods et al., 1986; Bell et al., 1989).

Secondly, S. typhimurium $\mathrm{H}_{6} \operatorname{PrpD}$ was reported to hydrate cis-aconitate at a rate comparable to 2-methylcitrate dehydration (but it failed to hydrate 2-methyl- 
cis-aconitate to 2-methylisocitrate), citrate was a poor substrate, and isocitrate was not a substrate (Horswill \& Escalante-Semerena, 2001). In contrast E. coli PrpD was unable to use cis-aconitate (or other substrates having double bonds, excluding 2-methyl-cis-aconitate which was not tested) but citrate and isocitrate were good substrates. The failure to detect hydration of cisaconitate by E. coli PrpD might reflect a very low affinity for cis-aconitate, and likewise for 2-methyl-cis-aconitate. This could be a desirable feature of an irreversible dehydratase, and if citrate and isocitrate are both converted to cis-aconitate the lack of reversibility would explain why PrpD is not an aconitase. In future it will be important to determine the specificities of both PrpD enzymes for each of the four stereoisomers of 2methylcitrate and to identify potential inhibitory effects that might stem from the presence of unnatural isomers or their dehydration products. The predominant isomers of 2-methylcitrate generated by mammalian citrate synthase are not identical to the natural isomer produced by the 2-methylcitrate synthases (VanRooyen et al., 1994; Brock et al., 2000, 2001) so the 2-methylcitrate dehydratase activity of PrpD was probably tested under suboptimal conditions with respect to its cognate substrate and the presence of an excess of potentially competing isomers. The latter also applies to the $S$. typhimurium enzyme, where synthetic substrate containing all four isomers was used (Horswill \& EscalanteSemerena, 2001). This might account for some of the discrepancies between the two reports.

The differences in enzyme substrate specificities between the two species also extended to the aconitases. Compared to the $S$. typhimurium aconitases, $\mathrm{H}_{6} \mathrm{AcnA}$ and $\mathrm{H}_{10} \mathrm{AcnB}$, which are effective 2-methyl-cis-aconitate hydratases but very poor 2-methylcitrate dehydratases (shown for $\mathrm{H}_{6} \mathrm{AcnA}$ and assumed for $\mathrm{H}_{10} \mathrm{AcnB}$; otherwise PrpD would not be essential for propionate catabolism), the corresponding hydratase and dehydratase activities of the E. coli enzymes, AcnA and $A c n B$, were extremely low with the methylated substrates (Table 5). But again it should be noted that in both cases the enzymes were tested in the presence of a mixture of potentially inhibitory 2-methylcitrate isomers (VanRooyen et al., 1994). Nevertheless, these differences could explain why propionate is a good substrate for S. typhimurium but not for E. coli unless pre-adapted. Growth on propionate requires not only that the citric acid and 2-methylcitrate cycles operate simultaneously but also the glyoxylate cycle, which has been shown to be the source of oxaloacetate for propionate utilization rather than the phosphopyruvate carboxylation (Textor et al., 1997). This provides great opportunities for mutual interference and metabolic derangement which might be more acute in E. coli than in S. typhimurium. It has long been known that operation of the glyoxylate cycle is inhibited by lactate and pyruvate, and by generating pyruvate, propionate utilization might be limited by its inhibitory effect on this essential metabolic cycle. In E. coli the adaptation to propionate might involve subtle alterations of regulatory constraints controlling cofactor availability and metabolic flow, improving the ability of aconitase to convert 2-methyl-cis-aconitate to 2-methylisocitrate, allowing aconitase to function normally in the presence of potentially inhibitory methylated analogues, or derepressing another enzyme that can mediate this conversion. In the latter context it may be significant that partially purified YbhJ exhibited a weak 2-methyl-cisaconitate hydratase activity that might therefore function in the 2-methylcitrate cycle (Fig. 5). The very close proximity of the $y b h J$ gene to the lambda attachment site $(a t t \lambda)$ also raises the interesting possibility that the recombinant prophages previously shown to amplify a cis-aconitate hydratase upon induction (Wilde et al., 1986) might have promoted phage-mediated transcription of the flanking $y b b J$ gene after induction, rather than being $\lambda a c n$ phages per se.

Many of the questions concerning enzyme substrate specificities and the potential role of YbhJ in the 2methylcitrate cycle should be resolved ultimately when pure enzymes can be used with pure substrates and when physiological comparisons are made between strains of E. coli that are unadapted and adapted for growth on propionate. Also, despite the major difference concerning the requirement for iron-sulphur clusters, it is clear that the PrpD proteins both of S. typhimurium and E. coli have 2-methylcitrate dehydratase activity, and that PrpD is the source of the activity attributed to AcnC in the AcnAB-null strain of E. coli.

\section{ACKNOWLEDGEMENTS}

We thank Dr A. J. G. Moir for nucleotide and amino acid sequencing, Dr D. L. Court for kindly supplying DY329 for use in chromosomal gene replacement, and Drs Y. Tang and E. T. Ralph for samples of purified aconitases and NifS, respectively. This work was supported by a studentship from the Biotechnology and Biological Sciences Research Council (L.B.) and a project grant from The Wellcome Trust (J.R.G.).

\section{REFERENCES}

Alen, C. \& Sonenshein, A. L. (1999). Bacillus subtilis aconitase is an RNA-binding protein. Proc Natl Acad Sci US A 96, 1041210417.

Beinert, H. (1983). Semi-micro methods for analysis of labile sulfur and of labile sulfide plus sulfane sulfur in unusually stable iron-sulfur proteins. Anal Biochem 131, 373-378.

Beinert, H., Kennedy, M. C. \& Stout, C. D. (1996). Aconitase as iron-sulfur protein, enzyme and iron-regulatory protein. Chem Rev 96, 2335-2373.

Bell, P. J., Andrews, S. C., Sivak, M. N. \& Guest, J. R. (1989). Nucleotide sequence of the FNR-regulated fumarase gene (fumB) of Escherichia coli K-12. J Bacteriol 171, 3494-3503.

Bennett, B., Gruer, M. J., Guest, J. R. \& Thomson, A. J. (1995). Spectroscopic characterisation of an aconitase (AcnA) of Escherichia coli. Eur J Biochem 233, 317-326. 
Blattner, F. R., Plunkett, G., III, Bloch, C. A. \& 14 other authors (1997). The complete genome sequence of Escherichia coli K-12. Science 277, 1453-1470.

Bradbury, A. J., Gruer, M. J., Rudd, K. E. \& Guest, J. R. (1996). The second aconitase (AcnB) of Escherichia coli. Microbiology 142, 389-400.

Brock, M., Fischer, R., Linder, D. \& Buckel, W. (2000). Methylcitrate synthase from Aspergillus nidulans: implications for propionate as an antifungal agent. Mol Microbiol 35, 961-973.

Brock, M., Darley, D., Textor, S. \& Buckel, W. (2001). 2Methylisocitrate lyases from the bacterium Escherichia coli and the filamentous fungus Aspergillus nidulans. Characterization and comparison of both enzymes. Eur J Biochem 268, 3577-3586.

Chang, A. C. Y. \& Cohen, S. N. (1978). Construction and characterization of amplifiable multicopy DNA cloning vehicles derived from the P15A cryptic miniplasmid. J Bacteriol 134, 1141-1156.

Cole, S. T. \& Guest, J. R. (1980). Genetic and physical characterisation of lambda transducing phages $(\lambda f r d A)$ containing the fumarate reductase gene of Escherichia coli K12. Mol Gen Genet 178, 409-418.

Cunningham, L., Gruer, M. J. \& Guest, J. R. (1997). Transcriptional regulation of the aconitase genes (acnA and $a c n B)$ of Escherichia coli. Microbiology 143, 3795-3805.

Flint, D. H. \& Emptage, M. H. (1988). Dihydroxy acid dehydratase from spinach contains a $[2 \mathrm{Fe}-2 \mathrm{~S}]$ cluster. J Biol Chem 263, 3558-3564.

Flint, D. H., Emptage, M. H. \& Guest, J. R. (1992). Fumarase A from Escherichia coli: purification and characterization as an iron-sulfur cluster containing enzyme. Biochemistry 31, 1033110337.

Gerike, U., Hough, D. W., Russell, N. J., Dyall-Smith, M. L. \& Danson, M. J. (1998). Citrate synthase and 2-methylcitrate synthase: structural, functional and evolutionary relationships. Microbiology 144, 929-935.

Green, J., Bennett, B., Jordan, P., Ralph, E. T., Thomson, A. J. \& Guest, J. R. (1996). Reconstitution of the $[4 \mathrm{Fe}-4 \mathrm{~S}]$ cluster in FNR and demonstration of the aerobic-anaerobic transcription switch in vitro. Biochem J 316, 887-892.

Gruer, M. J. \& Guest, J. R. (1994). Two genetically-distinct and differentially-regulated aconitases (AcnA and AcnB) in Escherichia coli. Microbiology 140, 2531-2541.

Gruer, M. J., Artymiuk, P. J. \& Guest, J. R. (1997a). The aconitase family: three structural variations on a common theme. Trends Biochem Sci 22, 3-6.

Gruer, M. J., Bradbury, A. J. \& Guest, J. R. (1997b). Construction and properties of aconitase mutants of Escherichia coli. Microbiology 143, 1837-1846.

Hentze, M. W. \& Kuhn, L. C. (1996). Molecular control of vertebrate iron metabolism: mRNA-based regulatory circuits operated by iron, nitric oxide and oxidative stress. Proc Natl Acad Sci U S A 93, 8175-8182.

Horswill, A. R. \& Escalante-Semerena, J. C. (1997). Propionate catabolism in Salmonella typhimurium LT2: two divergently transcribed units comprise the prp locus at 8.5 centisomes, $p r p R$ encodes a member of the sigma-54 family of activators, and the prpBCDE genes constitute an operon. J Bacteriol 179, 928-940.

Horswill, A. R. \& Escalante-Semerena, J. C. (1999a). Salmonella typhimurium LT2 catabolizes propionate via the 2-methylcitric acid cycle. J Bacteriol 181, 5615-5623.
Horswill, A. R. \& Escalante-Semerena, J. C. (1999b). The prpE gene of Salmonella typhimurium LT2 encodes propionyl-CoA synthetase. Microbiology 145, 1381-1388.

Horswill, A. R. \& Escalante-Semerena, J. C. (2001). In vitro conversion of propionate to pyruvate by Salmonella enterica enzymes: 2-methylcitrate dehydratase (PrpD) and aconitase enzymes catalyse the conversion of 2-methylcitrate to 2-methylisocitrate. Biochemistry 40, 4703-4713.

Jordan, P. A., Tang, Y., Bradbury, A. J., Thomson, A. J. \& Guest, J. R. (1999). Biochemical and spectroscopic characterisation of Escherichia coli aconitases (AcnA and AcnB). Biochem J 344, 739-746.

Kennedy, M. C., Emptage, M. H., Dreyer, J.-L. \& Beinert, H. (1983). The role of iron in the activation-inactivation of aconitase. J Biol Chem 258, 11098-11105.

Laemmli, U. K. (1970). Cleavage of structural proteins during the assembly of the head of bacteriophage T4. Nature 277, 680-685.

Lakshmi, T. M. \& Helling, R. B. (1976). Selection for citrate synthase deficiency in icd mutants of Escherichia coli. J Bacteriol 127, 76-83.

Lennox, E. S. (1955). Transduction of linked genetic characters of host by bacteriophage P1. Virology 1, 190-206.

Lauble, H., Kennedy, M. C., Beinert, H. \& Stout, C. D. (1992). Crystal structures of aconitases with isocitrate and nitroisocitrate bound. Biochemistry 31, 2735-2748.

Marsh, P. (1986). ptac-85, an Escherichia coli vector for expression of non-fusion proteins. Nucleic Acids Res 14, 3603.

Miles, J. M. \& Guest, J. R (1984). Complete nucleotide sequence of the fumarase gene fumA of Escherichia coli. Nucleic Acids Res 12, 3631-3642.

Prodromou, C., Artymiuk, P. J. \& Guest, J. R. (1992). The aconitase of Escherichia coli. Eur J Biochem 204, 599-609.

Robbins, A. H. \& Stout, C. D. (1989). The structure of aconitase. Proteins 5, 289-312.

Sambrook, J., Fritsch, E. F. \& Maniatis, T. (1989). Molecular Cloning: a Laboratory Manual, 2nd edn. Cold Spring Harbor, NY: Cold Spring Harbor Laboratory.

Shimada, K., Weisberg, R. A. \& Gottesman, M. E. (1973). Prophage lambda at unusual chromosomal locations. II. Mutations induced by bacteriophage lambda in Escherichia coli K12. J Mol Biol 80, 297-314.

Somerville, G., Miloryak, C. A. \& Reitzer, L. (1999). Physiological characterization of Pseudomonas aeruginosa during exotoxin A synthesis: glutamate, iron limitation, and aconitase activity. $J$ Bacteriol 181, 1072-1078.

Tang, Y. \& Guest, J. R. (1999). Direct evidence for mRNA binding and post-transcriptional regulation by Escherichia coli aconitases. Microbiology 145, 3069-3079.

Textor, S., Wendisch, V. F., De Graaf, A. A., Müller, U., Linder, M. I., Linder, D. \& Buckel, W. (1997). Propionate oxidation in E. coli: evidence for operation of a methylcitrate cycle in bacteria. Arch Microbiol 168, 428-436.

VanRooyen, J.P. G., Mienie, J., Erasmus, E., DeWet, W. J., Ketting, D., Duran, M. \& Wadman, S. K. (1994). Identification of the stereoisomeric configurations of methylcitric acid produced by $s i$-citrate synthase and methylcitrate synthase using capillary gas-chromatography mass-spectrometry. J Inherit Metab Dis 17, 738-747.

Wilde, R. J., Jeyaseelan, K. \& Guest, J. R. (1986). Cloning of the aconitase gene (acn) of Escherichia coli K12. J Gen Microbiol 132, 1763-1766. 
Wilson, T. J. G., Bertrand, N., Tang, J.-L., Feng, J.-X., Pan, M.-Q., Barber, C. E., Dow, J. M. \& Daniels, M. J. (1998). The $r p f A$ gene of Xanthomonas campestris pathovar campestris, which is involved in the regulation of pathogenicity factor production, encodes an aconitase. Mol Microbiol 28, 961-970.

Woodland, M. P. \& Dalton, H. (1984). Purification and characterization of component A of the methane monooxygenase from Methylococcus capsulatus (Bath). J Biol Chem 259, 53-59.

Woods, S. A., Miles, J. S., Roberts, R. E. \& Guest, J. R. (1986). Structural and functional relationships between fumarase and aspartase: nucleotide sequences of the fumarase (fumC) and aspartase (aspA) genes of Escherichia coli K12. Biochem J 237, 547-557.

Yu, D., Ellis, H. M., Lee, E.-C., Jenkins, N. A., Copeland, N. G. \& Court, D. L. (2000). An efficient recombination system for chromosome engineering in Escherichia coli. Proc Natl Acad Sci U S A 97, 5978-5983.

Received 23 July 2001; revised 28 August 2001; accepted 30 August 2001. 